\title{
Demonstrating How Urban Morphology Matters: Reaching Beyond the Geometry of Building Design, Construction Systems and Occupational Behaviours and Towards Broader Context-Specific Transformations
}

\author{
Mark Deakin \\ School of Engineering and the Built Environment \\ Edinburgh Napier University, UK \\ E-Mail: m.deakin@ napier.ac.uk \\ Alasdair Reid \\ The Institute for Sustainable Construction \\ Edinburgh Napier University, UK \\ E-Mail: al.reid@napier.co.uk \\ Miss Fiona Campbell \\ The Institute for Sustainable Construction \\ Edinburgh Napier University, UK \\ E-Mail: fh.campbell@napier.ac.uk
}

Received: August 14, 2013 Accepted: September 1, 2013

doi:10.5296/emsd.v2i2.4307 URL: http://dx.doi.org/10.5296/emsd.v2i2.4307

\begin{abstract}
Recent studies of urban morphology, suggest the design, layout and texture of district centres, neighbourhoods and buildings have as much a bearing on levels of energy consumption and rates of carbon emission as either buildings or their occupation. They suggest urban morphology matters and both the design, layout and texture of district centres, neighbourhoods and buildings are as significant in setting levels of energy consumption and
\end{abstract}


rates of carbon emission as the occupation and use of such structures. This paper aims to reiterate this message and demonstrate how urban morphology does matter. Not only with respect to the geometry (i.e. surface and volume of the building design typologies), construction systems, or occupational behaviours, that such studies drawn particular attention to, but with regards to a matter which they have hitherto overlooked. That is with regards to the potential which the planning, (re)development, design and layout of district centres and their neighbourhoods as context-specific transformations have, to not only lower levels of energy consumption and rates carbon emission, but mitigate the climate change associated with the occupation and use of buildings. In meeting this aim and demonstrating how urban morphology does matter, the paper shall draw upon the experiences of a transformation taking place in the London Borough of Sutton known as the Hackbridge project: a mass retrofit proposal designed as a sustainable suburb with distinct centres, neighbourhoods and buildings, laid out and contextualised as an energy efficient-low carbon zone.

Keywords: urban morphology, design, layout, texture, context-specific, transformation, mass-retrofit, sustainable suburb, energy efficiency, low carbon zones

\section{Urban Morphology, Design, Layout and Texture}

The article by (Ratti, Baker and Steemers 2005) offers an account of why urban morphology, design, layout and texture matters by way of and through what might be best described as a coded critique of how the "building scientist" approaches the matter of energy performance. That is to say, by way of and through a coded critique of the approach which assigns buildings a set of values to be read-off by type of design, system of construction and occupant behaviour independent of their environment. This is because for (Ratti, Baker and Steemers 2005) such a scientific reading of the subject offers too narrow a perspective on the design of buildings, their construction systems and occupational behaviours as determinants of energy performance and for the simple reason it fails to explain the high degree of variance between the values assigned to them and those experienced. For them putting this right (i.e. explaining this variance in energy performance in terms of the gap between theory and practice) means that we need to transcend the all too narrow perspective of energy performance offered by the building scientist and broaden it out so as to begin accounting for the complex environmental processes at play in such determinations.

Ultimately this means understanding the relationship that buildings have to their environment both by way of urban morphology and through the context-specific form which building design, construction systems and occupational behaviour takes on. This is because for these authors urban morphology provides a critical insight into the context-specific form of the building designs, construction systems and occupational behaviour that is currently missing and which limits what is known about energy performance. Focussing on the design, construction and occupational performances within the cities of London, Toulouse and Berlin, they find that variation in the consumption of energy by building, system and behaviour, is something which cannot be explained by way of surface to building volume ratios alone, but through the relationship the passive to non-passive areas of their district centres and 
neighbourhoods also have to one another. Together they propose these geometries account for up to $10 \%$ of the variance in energy performance previously left unexplained.

As such this article serves to confirm the maxim that urban morphology does matter and should be seen as an integral component of any energy performance assessment because knowledge of their context-specific form can account for up to $10 \%$ of the variance between the assigned values of building designs, construction systems and occupational behaviour. However, while this reaffirmation of urban morphology in terms of context-specific form offers a critical insight of some magnitude, it has to be recognised that it says little about how such knowledge of building design, construction systems and occupational behaviour should be acted on to start transforming either the neighbourhoods, or district centres of cities of which they form an integral part. For apart from telling us the urban morphology and the context-specific forms this takes on should not be ignored and ought to be integrated into the design of buildings, construction systems and occupational behaviour, we are left none the wiser as to how this broadening out of the subject can achieve this. While (Salat 2009) and (Bourdic, Serge and Nowacki 2012,) have recently sought to develop the surface-to-building volumes and passive-to-non-passive areas as the means to support such an integration, we find that here again these tend to be represented in strictly technical terms, distinct from either the social, environmental, or economic relationships they in turn relate to. This is despite both authors clearly acknowledging the criticality of such measures.

As the rest of this paper shall serve to demonstrate, asking about the social, environmental and economic relationship that everyone seems to agree urban morphology is not only grounded in, but which in a large part sets out the specific context for the forms of building design, construction systems and occupational behaviours drawn attention to, immediately begins to shift the point of emphasis. For in emphasising the relational aspects of urban morphology, immediately begins to shift away for the development of diagnostic tools for analysing the shortcoming of building designs, construction systems and occupational behaviours and towards the value of deploying building-to-surface volumes and passive-to-non passive areas as performance measures.

Grounding the subject in this manner does much to not just reaffirm the significance of urban morphology as a technical matter, but positively transform the subject into a social, environmental and economic relationship whose forces do much to set the surface-to-area and passive-to-non-passive area ratios in the specific forms (i.e. neighbourhoods of district centres) which (Ratti, Baker and Steemers 2005) drawn particular attention to. This positive transformation of urban morphology and re-grounding of what it means in social, environmental and economic terms shall be demonstrated by way of and through a case study analysis and account of the aforementioned surface-to-building ratios and passive-to-non-passive areas in what shall be termed "an active and integrated institutional arrangement". That is, by way of a mass retrofit proposal which is actively integrated as a technical, social, environmental and economic relationship through a process of urban regeneration whose strategy, vision, district-wide Masterplan, programme of neighbourhood renewal and redevelopment of suburban housing estates, is in turn capable of sustaining the on-going transformation of Hackbridge into an energy efficient, low carbon zone. 
In offering a bottom-up account of how institutions within the City of London can begin to plan for and sustain the development of energy efficient-low carbon zones, the case-study also provides the opportunity to extend the seminal work of (Ratti, Baker and Steemers 2005) on the morphology of urban geometry and advance this research by drawing particular attention to the type of social baseline assessments needed to legitimate, not only the strategic value of such context-specific transformations, but their practical worth as building-to-surface ratios and passive-to-non-passive areas, themselves able to meet the standards of environmental sustainability required under the 2008 UK Climate Bill.

A case-study

As a case-study, the following offers an abridged version of a more extensive article published elsewhere (Deakin, M., Campbell, F. and Reid, A. 2012a) (Deakin, M., Campbell, F. and Reid, A. 2012b). While these articles drew particular attention to the underlying theoretical and methodological needs of mass-retrofits proposals, the object of this case-study lies elsewhere and with understanding the morphology of the built environment, both by way of and through the context-specific form their design, construction, occupational and use take on as a set of energy and carbon related performances.

As a suburb within the London Borough of Sutton, Hackbridge is home to approximately 8,000 people. The area is largely residential and the housing comprises 18th century listed cottages, late 19th century terraced houses, inter-war semi-detached homes and BedZED, the internationally recognised development of 100 homes built to sustainable design principles in 2000 .

In 2005, Sutton Council stated its commitment to move towards One Planet Living as a concept based around 10 sustainability principles developed by BioRegional. This commitment is set out in Sutton's (2008) Draft Development Plan Document and defined in BP61 of the Core Planning Strategy] as a:

“... key long-term target ...to reduce the ecological footprint of residents to a more sustainable level of 3 global hectares per person by 2020 from the current '3-planet' baseline of 5.4 global hectares. To deliver this Vision, the Council is working in partnership with BioRegional to prepare a 'Sustainability Action Plan' based on the 10 One Planet Living principles of zero carbon; zero waste; sustainable transport; local and sustainable materials; local and sustainable food; sustainable water; natural habitats and wildlife cultural and heritage; equity and fair trade; and health and happiness."

The Core Planning Strategy also states that Hackbridge:

“...will be the focus for a flagship sustainable [urban] regeneration project that brings about the renewal of the fabric of the area through environmentally innovative mixed-use redevelopment schemes."

The urban regeneration strategy

In promoting this urban regeneration strategy, BioRegional have taken on the responsibility of managing the project and drafting a Sustainability Action Plan setting out how the renewal 
of the fabric shall be environmentally innovative in terms of the mixed use redevelopment schemes their joint statement on One Planet Living sets out.

The vision of the master-plan

Under this strategy a Masterplan has been commissioned from Tibbalds Planning and Urban Design. As a strategic document sign-posting the way ahead, the vision which the master-plan lays down for the Borough sets out the programme of renewal that is needed for such a redevelopment scheme to underpin the joint statement on One Planet Living and actively support the transformation of Hackbridge into a "sustainable suburb".

The Sustainable Suburb Charter, a document complementing the plan's vision, programme of renewal and redevelopment, also draws out 13 additional requirements. These being to:

- create a local centre for Hackbridge;

- develop high-quality pedestrian and cycle routes;

- for the redevelopment to meet $20 \%$ of all Sutton's new housing target (including social housing);

- increase the amount of employment opportunities for local residents;

- meet the requirements of the area's population growth, via new schools, new health facilities, etc;

- provide easily accessible green and open spaces

- for the redevelopment to provide opportunities for community engagement;

- manage and maintain areas specifically for bio-diversity

- reduce the disparity in residents' life expectancy, and obesity in general;

- achieve maximum energy efficiency "in all households, businesses and public buildings in the area";

- achieve a recycling rate higher than the average for London and water consumption rates lower than the national average;

- pilot parts of the South London Joint Waste Management Plan;

- establish a resource pool and evidence base for all forms of sustainability.

It is this institutional arrangement that both the Masterplan and Charter make explicit reference to as the particular means by which Sutton can sustain the regeneration of Hackbridge in line with BioRegional's principles of "One Planet Living". Here particular attention is given to the means by which a mass retrofit of the area's residential sector can generate reduced rates of energy consumption and lower levels of carbon emissions.

\section{The Energy Options Appraisal}

The Energy Options Appraisal for Domestic Buildings, produced by Parity Projects in April 2008, sets out the "programme of work" for improving the energy efficiency and carbon emissions of the housing stock. It assesses the rates of energy consumption and levels of carbon emissions for the stock of housing within Hackbridge (as designated in the Masterplan) as part of the surface to building volume ratio. Brief attention is also given to profiling the 
resident community and referencing Census (2001) returns for the London Borough of Sutton. This analysis also details a number of energy efficiency measures that can be taken in order to turn the area under investigation into a low carbon zone.

While all very useful, the environmental profile advanced by Parity Projects is found wanting for the reason the Energy Options Appraisal is unclear as to whether the benefits generated from the forecast levels of energy consumption and carbon emissions will be spread equally amongst all residents. The explanation for this is simple: it is because, in order to clarify the distribution of benefits generated, it is first of all necessary for the institutional arrangement supporting the regeneration to first of all "baseline" the social-demographic composition of Hackbridge. Then in the second instance, go on and draw upon the results of this analysis to assess whether this "innovative" environment has the capacity to carry the energy consumption and carbon emissions targets set for this redevelopment. This in turn will allow a judgement to be made as to whether the process of urban regeneration has the means to sustain any such energy efficient and low carbon (re)development of the suburb.

In seeking to fill these gaps in the existing Energy Options Appraisal, the case-study has sought to establish:

- whether the environmental profile generated is capable of not only being baselined in socio-demographic terms, but drawn upon as the means to evaluate if the benefits of the mass retrofit can be spread equally amongst the residents;

- or whether the costs emerging from the action are unevenly distributed across the structure of tenure within the housing market and if this undermines the claims made about the environmental sustainability of the action.

The assumption underlying the types of profiling exercises found in the existing Energy Options Appraisal suggests they do legitimate actions of this type and in turn, are effective in championing environmental sustainability. This is the assumption which the case-study seeks to investigate. Set within this emerging debate on the environmentally sustainability of urban regeneration, the specific objectives of this examination into the mass retrofit proposal are to:

- develop an environmental profile for the proposal that is based upon the regeneration boundary set out in the Masterplan, energy consumption and carbon emission data sourced from the Energy Options Appraisal;

- draw upon official statistical data currently available to analyse the social and demographic structure within the regeneration boundary and baseline the potential there is for the mass retrofit to transform Hackbridge into a sustainable suburb;

- use the outcomes of this social baseline analysis to review whether the energy-saving and carbon reduction measures can transform Sutton into a sustainable suburb and if this is achievable without burdening any residents with additional environmental cost.

\subsection{The Environmental Profile}

This profiling exercise sub-divides the stock of residences into six house types and is used to calculate both the energy savings and carbon emissions reductions generated from the range 


\section{Macrothink}

Environmental Management and Sustainable Development

ISSN 2164-7682

2013, Vol. 2, No. 2

of retrofit options. Figure 1 shows the energy consumption and carbon emissions emanating from the collective housing stock within Hackbridge.

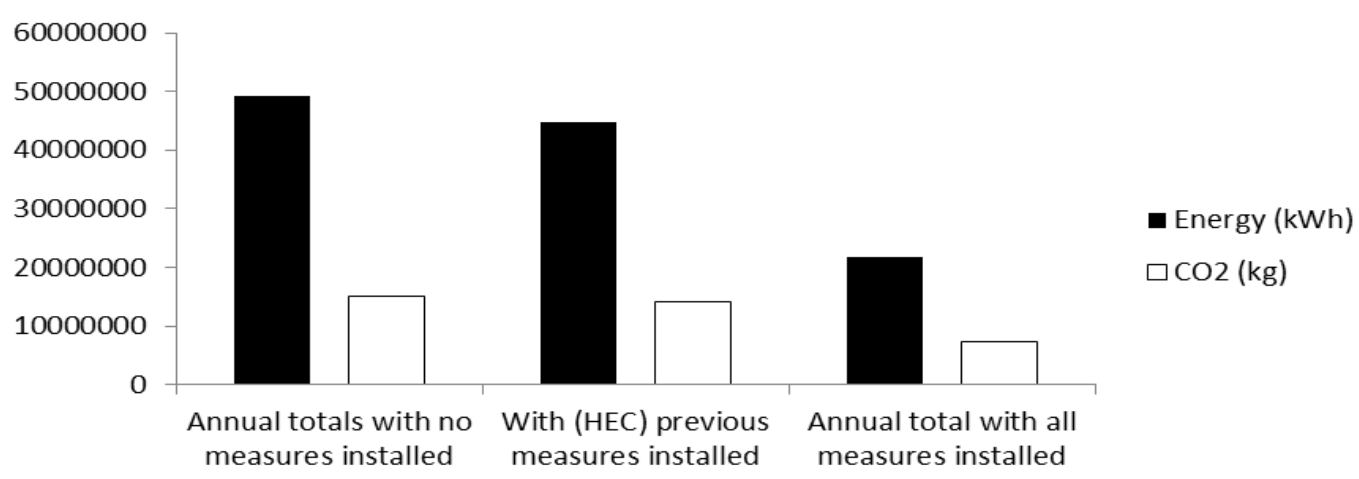

Figure 1. Potential Annual Energy and $\mathrm{CO}_{2}$ Reductions. Source: Energy Options Appraisal (2008)

The paired columns to the right of Figure 1 illustrate the potential energy savings and $\mathrm{CO}_{2}$ reductions assuming all the recommendations outlined within the report are taken up. The forecasted annual reductions if all measures are installed are predicted to result in $56.0 \%$ less energy consumption and 51.2\% less $\mathrm{CO}_{2}$ emissions from 1990 levels.

Figures 2 and 3 list the cost of the works needed for the retrofit to lower the levels of energy consumption and reduce carbon emissions. In some cases, alternatives are provided, such as in the proposed thickness of loft insulation. Both figures highlight these alternatives in grey.

\begin{tabular}{|c|c|}
\hline Measure & Total Cost \\
\hline Loft Insulation - 300mm & $£ 481,387$ \\
\hline Loft Insulation - 400mm & $£ 569,936$ \\
\hline Draught Proofing & $£ 414,132$ \\
\hline Turn Heating from 18 to 17 & $£ 0$ \\
\hline $\begin{array}{l}\text { Boiler for One Hour Less Per } \\
\text { Day (Controls Required) }\end{array}$ & $£ 0$ \\
\hline Energy Saving Light Bulbs & $£ 165,599$ \\
\hline Efficient Appliances & $£ 599,922$ \\
\hline TOTAL & $£ 1,661,040$ \\
\hline $\begin{array}{l}\text { AVERAGE COST } \\
\text { PER HOUSEHOD }\end{array}$ & $£ 691$ \\
\hline
\end{tabular}

Figure 2. The cost of basic measures. Energy Options Appraisal (2008).

Figure 2 lists basic measures assumed to be adopted by a high proportion of households without the need for professional assistance. These measures can be carried out immediately. The DIY percentage listed is the envisaged capability of residents to fulfil this requirement. The average cost of implementing such measures will be $£ 691$ per property. 


\begin{tabular}{|l|l|}
\hline Measure & Total Cost \\
\hline Secondary Glazing & $£ 1,463,056$ \\
\hline Solid Wall Insulation (Internal) & $£ 6,328,197$ \\
\hline Solid Wall Insulation (External) & $£ 5,709,127$ \\
\hline Under Floor Insulation & $£ 1,281,581$ \\
\hline Heat Exchange Ventilation & $£ 1,556,069$ \\
\hline Cavity Wall Insulation & $£ 265,607$ \\
\hline Double Glazing & $£ 4,093,861$ \\
\hline Triple Glazing & $£ 5,018,332$ \\
\hline Boiler Replacement & $£ 973,792$ \\
\hline $\begin{array}{l}\text { Solar Water Heating (with } \\
\text { ScaffoldingReq'd) }\end{array}$ & $£ 5,512,950$ \\
\hline $\begin{array}{l}\text { Solar Water Heating (no Scaffolding } \\
\text { Req'd) }\end{array}$ & $£ 4,608,990$ \\
\hline Solar Voltaics & $£ 4,946,103$ \\
\hline TOTAL & $£ \mathbf{2 5 , 8 0 2 , 1 4 6}$ \\
\hline $\begin{array}{l}\text { AVERAGE COST PER } \\
\text { HOUSEHOLD }\end{array}$ & $£ \mathbf{1 0 , 7 3 7}$ \\
\hline
\end{tabular}

Figure 3. The cost of more complex measures. Energy Options Appraisal (2008).

Figure 3 lists those measures which are mostly outside of the capability of households and instead require professional installation by qualified personnel. Implementing such measures will cost on average $£ 10,737$ per property.

\begin{tabular}{|l|l|l|l|}
\hline & $\begin{array}{c}\text { No. of } \\
\text { Households }\end{array}$ & Total Cost & $\begin{array}{c}\text { Average Cost per } \\
\text { household }\end{array}$ \\
\hline Hackbridge Study Area & 2403 & $£ 27,463,186$ & $£ 11,429$ \\
\hline $\begin{array}{l}\text { Hackbridge Study Area: } \\
\text { Owner Occupied (73\%) }\end{array}$ & 1754 & $£ 20,046,466$ & $£ 11,429$ \\
\hline
\end{tabular}

Figure 4. average cost per household. Source: Energy Options Appraisal (2008).

Figure 4 shows the total cost of implementing all the proposed measures, both DIY and professional, to be $£ 27,463,186$. With an average $73 \%$ owner occupation the cost of implementing such measures within this sector is $£ 20,046,466$ or $£ 11,429$ per property within the study area.

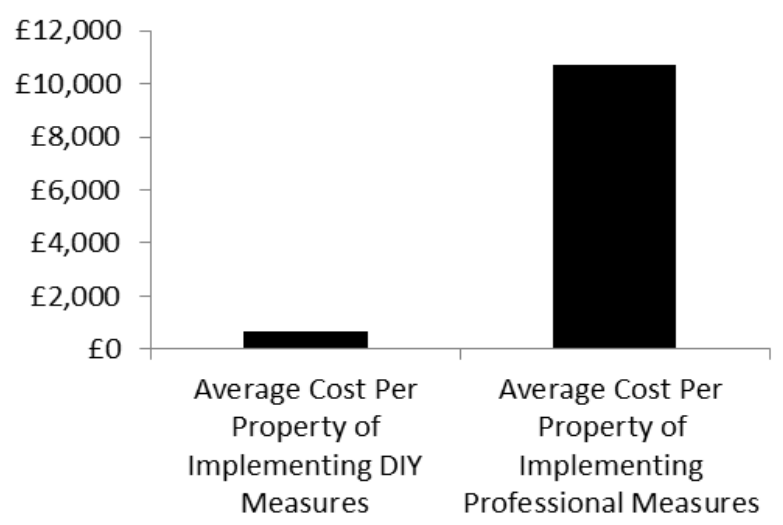

Figure 5. Average cost of DIY and professional measures. Source: Energy Options Appraisal (2008). 


\section{Ml Macrothink}

Environmental Management and Sustainable Development

ISSN 2164-7682 2013, Vol. 2, No. 2

In accordance with the terms of reference laid down for the retrofit, the costings are limited to those items of expenditure incurred by households in the owner-occupied and private-rented sector. Households in the social-rented sector are not factored into this costing and do not to form part of the retrofit proposal.

\section{Hackbridge by house type}

This profiling exercise goes on to identify 6 house types within the regeneration boundary: House Type B; House Type C; House Type F, House Type I, House Type J and House Type L. Variations within House Type F within the Energy Options Appraisal appear to have been based upon dwelling size rather than any significant difference in design so the "sub-types" within this group have been aggregated for Figure 6 .

\begin{tabular}{|l|l|l|l|}
\hline House type & Construction Date & No. of Properties & $\%$ \\
\hline L & Post 2001 & 57 & 2 \\
\hline I J & $1972-2000$ & 872 & 37 \\
\hline F & $1939-1959$ & 913 & 38 \\
\hline C & $1918-1938$ & 121 & 5 \\
\hline B & Pre 1918 & 440 & 18 \\
\hline \multicolumn{2}{|r|}{$\mathbf{2 4 0 3}$} & $\mathbf{1 0 0}$ \\
\hline
\end{tabular}

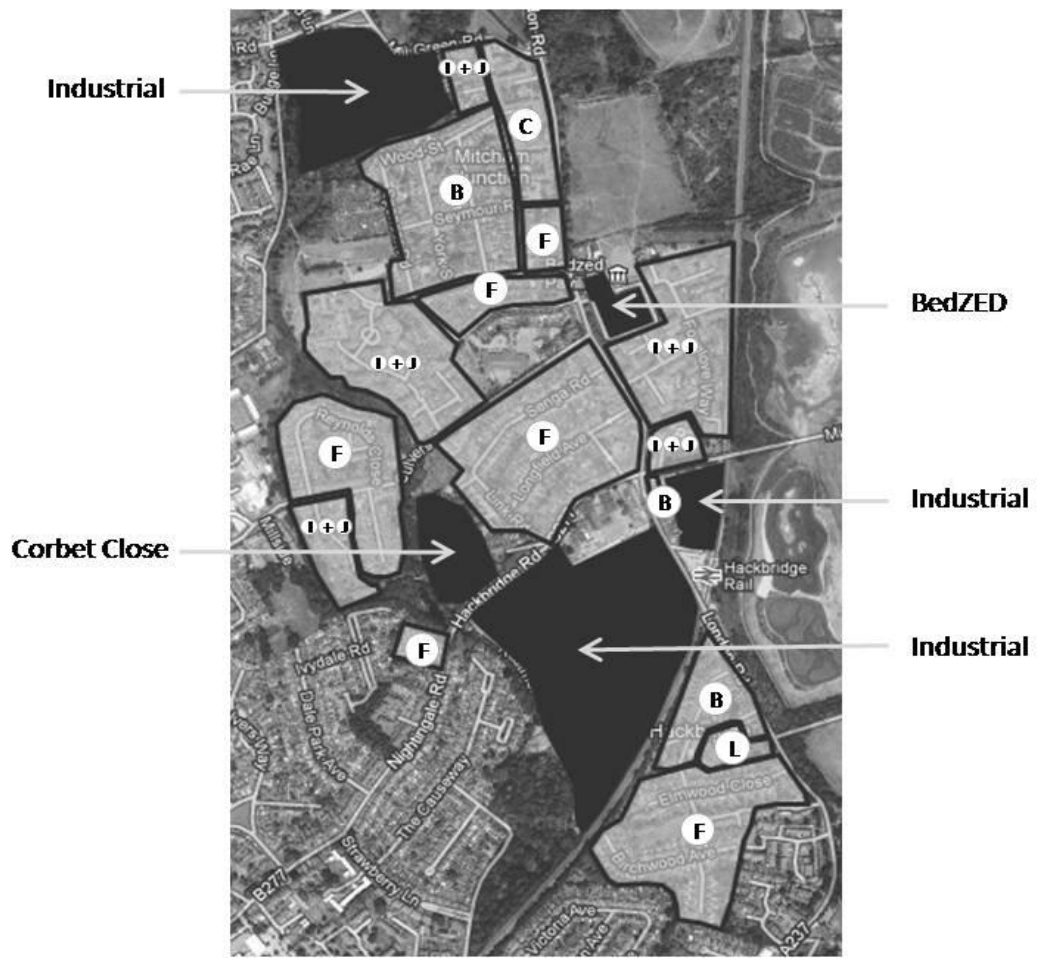

Figure 6. Hackbridge by House Type

Source: Energy Options Appraisal (2008)

Here Hackbridge is identified as having a high proportion of housing stock built post 1972 $(39 \%)$ and are likely to already have cavity insulation already installed. Similarly, those properties built pre-1939 (23\%) are likely to have been built with solid single skin external 


\section{I Macrothink}

Environmental Management and Sustainable Development

ISSN 2164-7682 2013, Vol. 2, No. 2

walls and therefore are unable to receive cavity wall insulation. The Energy Options Appraisal suggests that remedial works targeted at the older housing stock will deliver the greatest improvements, whilst conceding that the necessary works are often more invasive and costly.

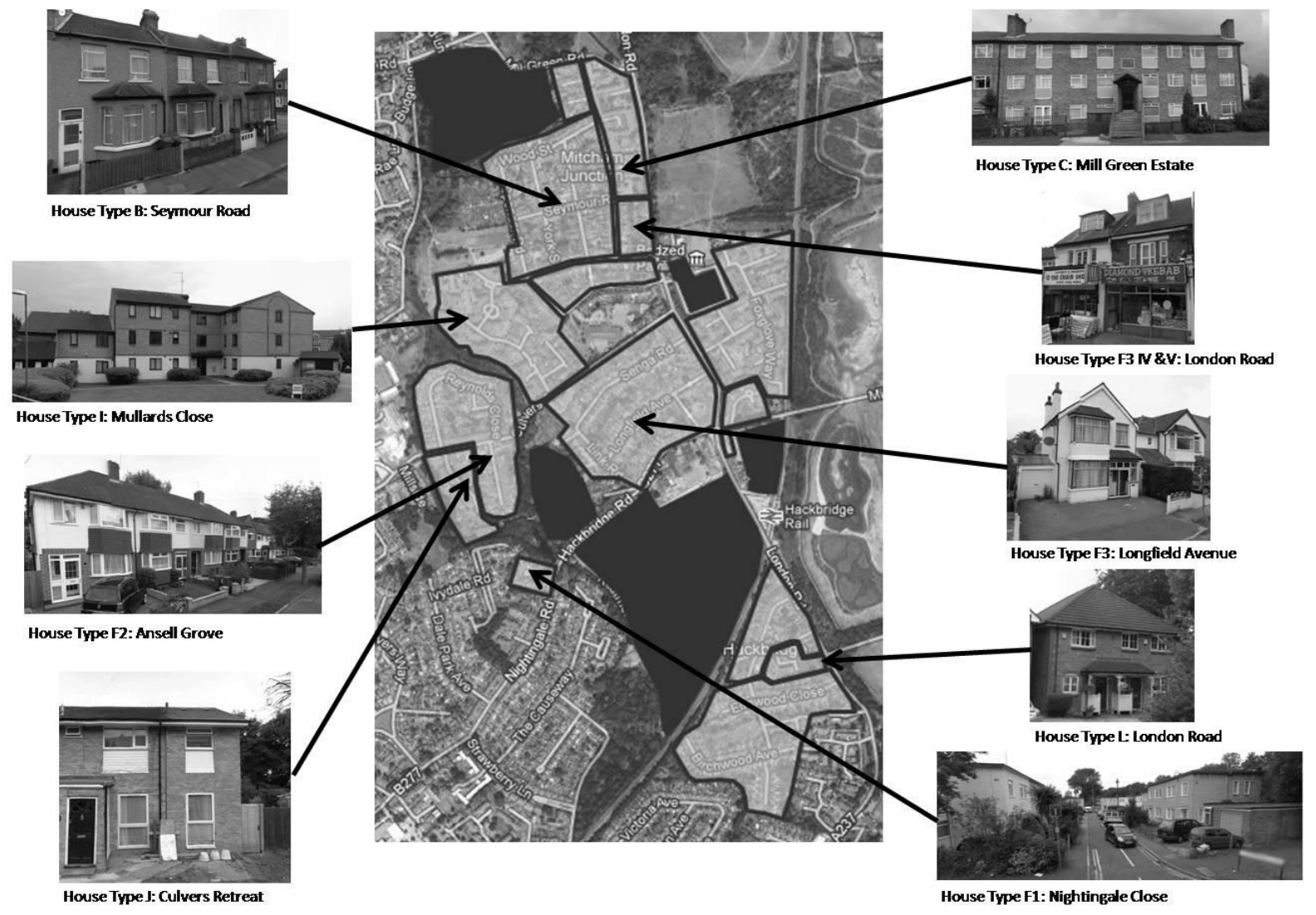

Figure 7. Hackbridge by house type location - images

Energy consumption and $\mathrm{CO}_{2}$ emissions by house type

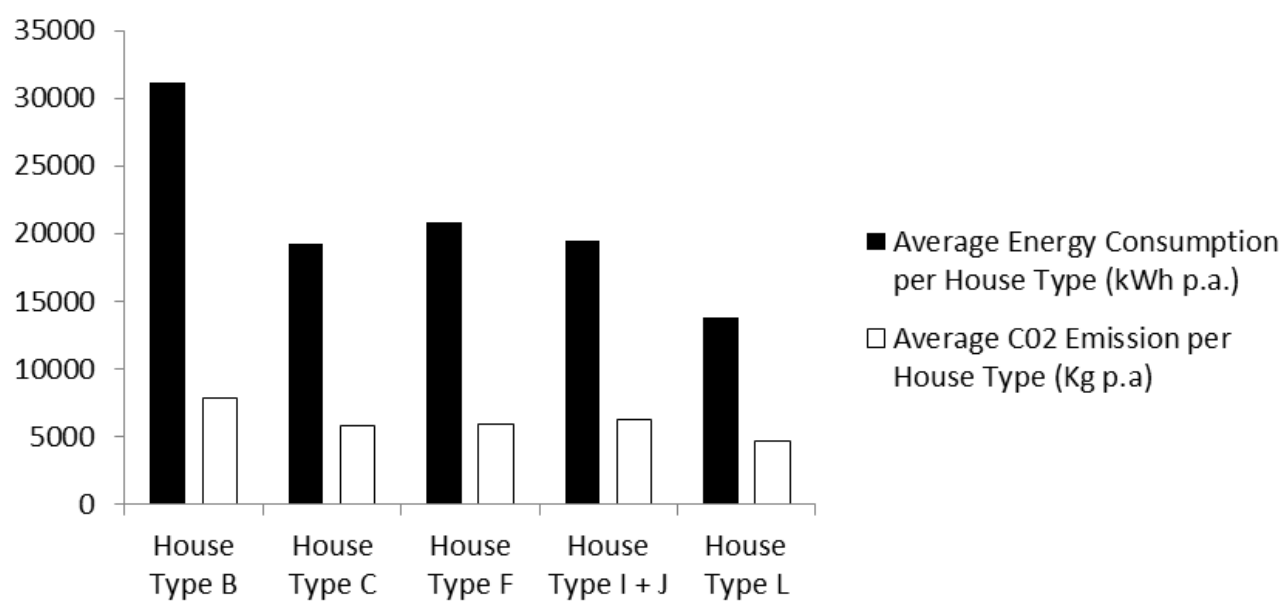

Figure 8. Average annual energy consumption and $\mathrm{CO}_{2}$ emissions per house type Source: Energy Options Appraisal (2008). 


\section{Macrothink}

Figure 8 shows that, in general, the older house types use more energy than the newer property types. Whilst energy consumption in Type B dwellings is highest, Type L homes consume the least energy. Similarly, it can be seen that the older housing stock (Type B, Type $\mathrm{C}$ and Type $\mathrm{F}$ ) has a higher rate of $\mathrm{CO}_{2}$ emission than the newer properties. This is demonstrated in Figure 8 by Type B (pre 1918) dwellings, which feature the highest rates of $\mathrm{CO}_{2}$ emission and Type $\mathrm{L}$ (post 2001) which produce the lowest rates.

The following maps present a more detailed picture of energy consumption across the housing types. These have been collated using data from the Energy Options Appraisal to indicate energy consumption and consequent $\mathrm{CO}_{2}$ emissions.
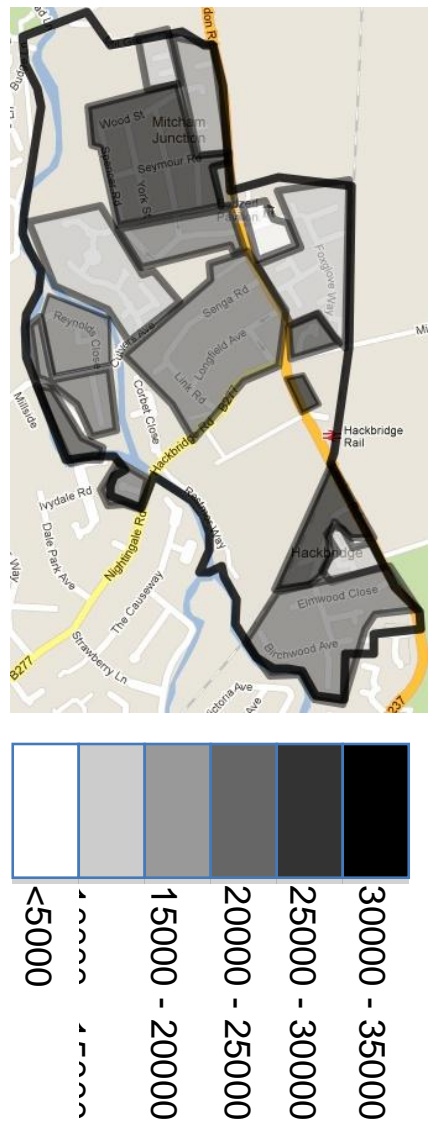

Figure 9: Energy consumption by housing type
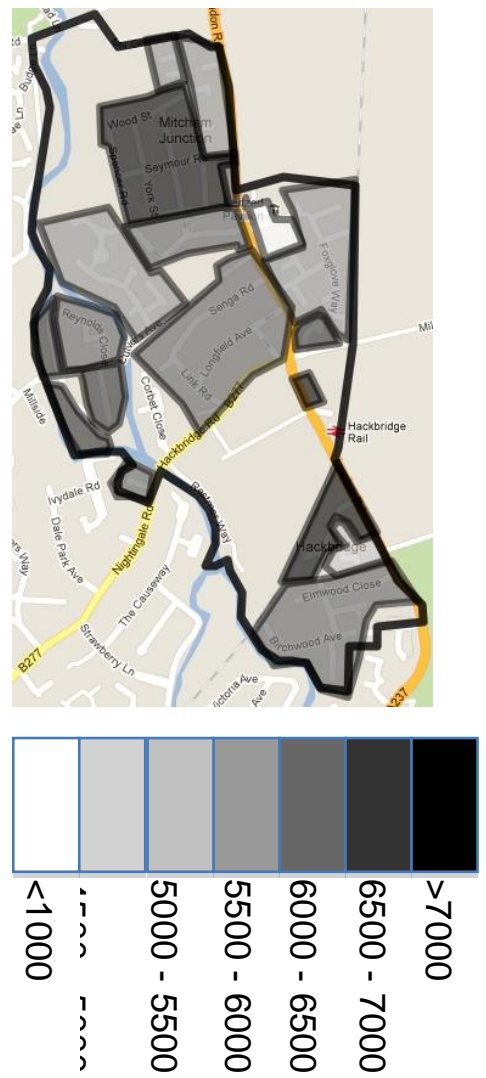

Figure 10: $\mathrm{CO}_{2}$ emissions by Housing Type

Figures 9 and 10 are arranged according to the groups of similar housing stock identified in The Energy Options Appraisal then coded according to their consumption of energy and emissions of $\mathrm{CO}_{2}$. Figure 9 shows pockets of high energy consumption (shown in dark grey) to the north and again in areas to the south. Similarly, pockets of low energy consumption can be seen across the map, in the north, where social deprivation is highest, and in the south where it is lowest.

Figure 10 shows the $\mathrm{CO}_{2}$ emissions detailed in the report. The method of calculating $\mathrm{CO}_{2}$ emissions in the report was to multiply the energy consumption by conversion factors of 0.43 


\section{Macrothink}

per kWh of electricity used and 0.18 per $\mathrm{kWh}$ of gas used. The highest emissions $(7,500-$ $8,000 \mathrm{~kg} \mathrm{CO}$ per annum) can be found in the north of the study area.

\subsection{The Social Baseline}

The maps draw on data returns from the Census 2001 and EIMD 2007 [adapted from data from the Office for National Statistics licensed under the Open Government Licence v.1.0]. The base unit for census data release is the Output Area - a cluster of adjacent postcode units incorporating approximately 312 residents. The base unit for the EIMD 2007 is the Lower Super Output Area (LSOA): these are built from groups of 4-6 OAs and constrained by the wards used for the 2001 census outputs.

\section{Classification of social groups}

The standard measures of social deprivation in England are the English Indices of Deprivation (EIMD), produced by the Government and compiled in 2007. These provide a ranking system whereby small geographical units, known as Lower Super Output Areas (LSOAs), are rated against 37 indicators and then ranked in relation to one another. LSOAs are home to approximately 1,500 people: there are a total of 32,482 LSOAs in England. As the LSOAs are ranked comparatively, rank 1 indicates the most deprived LSOA in England and rank 32,482 the least.

The outline for Hackbridge has been prepared using the Google "My Maps" function (Figure 11). A second map has subsequently been prepared showing the outlines of the Lower Super Output Areas spanning Hackbridge (identified using ONS Boundary Viewer and as shown in Figure 12). The map of the study area has been superimposed upon the map of the LSOAs to confirm appropriate coverage (Figure 13).

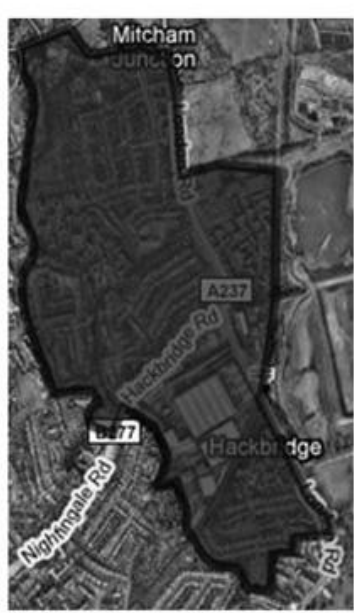

Figure 11

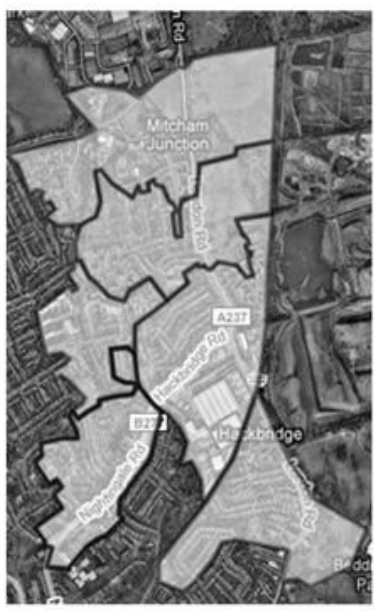

Figure 12

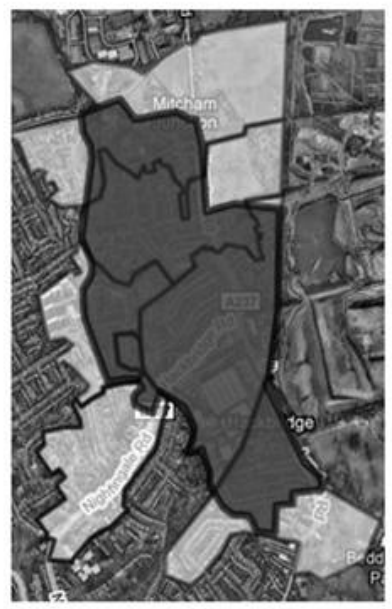

Figure 13

The Lower Super Output Areas within the Hackbridge study area (outlined in black), have been numbered from one to five and are shown in Figure 14. 


\section{Macrothink}

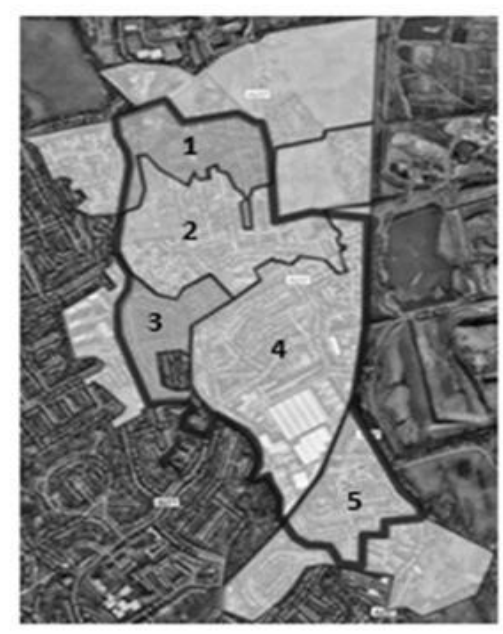

Figure 14. Hackbridge sub-sections by number

\section{EIMD 07 Overall Ranking}

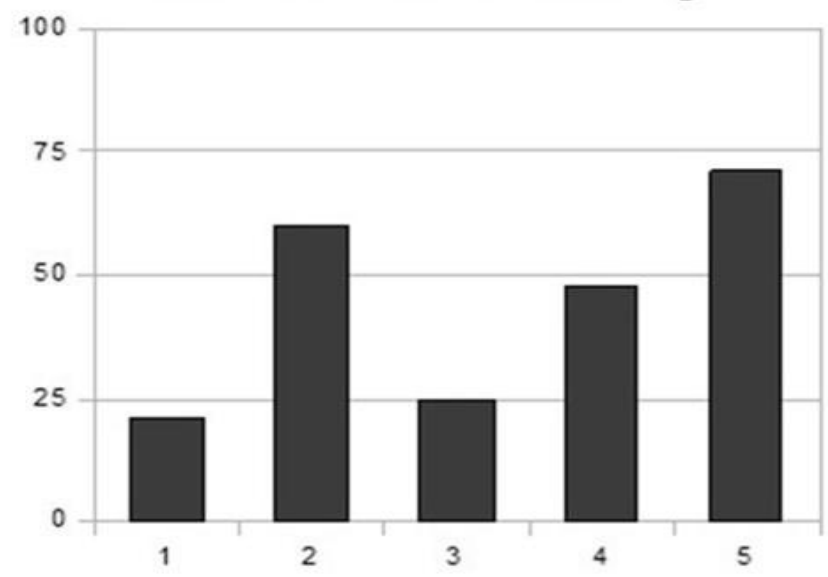

Figure 15. The overall deprivation ranking (where $100 \%$ is the least deprived in England)

As Figure 15 illustrates, Hackbridge is home to a large population who rank in the $50 \%$ least deprived in England. For the purposes of this report, each LSOA has been labelled from 1 to 5: areas within the 50\% least deprived in England are labelled 2 and 5. However, Hackbridge is also home to a population amongst the $25 \%$ most deprived in England - in the area labelled 1 - with an overall ranking of 6,768 (where 1 is the most deprived and 32,482 is the least). A second LSOA is ranked at the $25 \%$ mark; this is the small area labelled 3. However, as Figure 14 indicates, care must be taken when interpreting data returns for Area 3 as only half of the surface area is included within the Hackbridge Study Area (outlined in black). In total, three LSOAs, with an approximate combined population of 4,500, are home to people within the $50 \%$ most deprived in England.

In order to better understand these figures, it is important to consider each of the areas covered by the Indices in turn. The Indices of Deprivation 2007 were calculated across 7 domains: Income; Employment; Health and Disability; Education, Skills and Training; Barriers to Housing and Services; Living Environment and Crime.

\section{Deprivation across the domains}

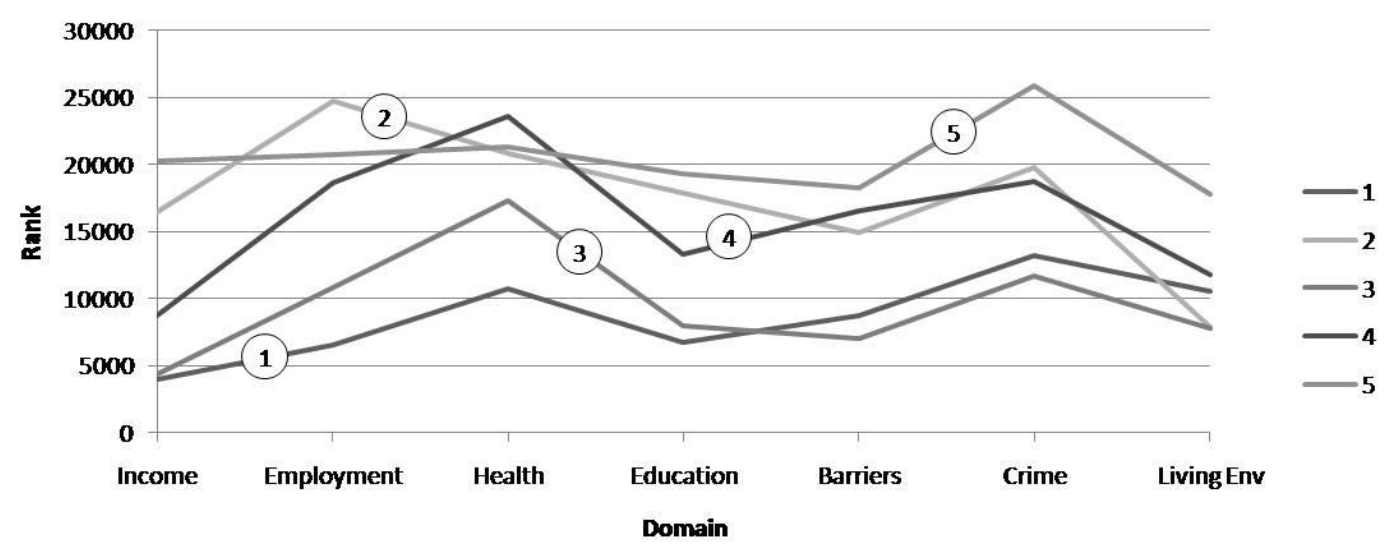

Figure 16. Multiple deprivation ranking (where a ranking of 32,482 is the least deprived in England). 
Figure 16 demonstrates deprivation ranking in the five LSOAs within the study area. These are labelled $1-5$ as shown in Figure 15. Findings from each domain are as follows:

- the Income Domain is designed to identify sections of the population experiencing income deprivation, with particular attention to those reliant upon various means-tested benefits. None of the LSOAs within the case study area fall within the $10 \%$ most income-deprived in England; however, two of Hackbridge's LSOAs are ranked within the $20 \%$ most deprived (Areas 1 and 3) and one is ranked within the 30\% most deprived (Area 4). The actual score given to each LSOA represents the area's income deprivation rate. This means that in Area 1,32\% of residents can be described as income-deprived. To the west, in Area 3,30\% of residents can be described as income deprived. By contrast, in Area 5 to the south of Hackbridge station, only $9 \%$ of residents are income-deprived.

- the EIMD 2007 conceptualises employment deprivation as "the involuntary exclusion of the working-age population from the world of work". The highest rate of employment deprivation in Hackbridge is $15 \%$, seen in Area 1. This is in the $30 \%$ most deprived areas in England. By contrast, the area immediately south of this LSOA (Area 2) has an employment deprivation rate of 5\%; amongst the 20\% least deprived in England.

- the Health and Disability domain measures morbidity, disability and premature mortality in each given area. Area 1 is the most health-deprived, ranking within the $33 \%$ most deprived in England. Area 4 ranks within the 28\% least health-deprived in England.

- the Barriers to Housing and Services domain is calculated over two sub-domains: geographical barriers and so-called "wider" barriers, which includes issues relating to the affordability of local housing. Area 3 is the most deprived within the study area and is within the $22 \%$ most deprived in England.

- the Education, Skills and Training deprivation domain measures deprivation in educational attainment amongst children, young people and the working age population. Area 1 ranks at 21\% most deprived in England; its high ranking owing to the low rate of young people entering Higher Education each year. Area 3 ranks at 25\%; again largely due to its low HE progression rate.

- the Crime domain measures the rate of recorded crime for 4 major volume crime types: burglary, theft, criminal damage and violence. The EIMD 2007 proposes that this domain represents "the risk of personal and material victimisation at a small area level". In this domain, Area 3 is ranked within the $36 \%$ most deprived and Area 1 within the $41 \%$ most crime deprived. Area 5 ranks in the $20 \%$ least deprived in England, in terms of crime.

- the Living Environment domain is, in fact, calculated over two sub-domains: indoors and outdoors. Indoors, the domain identifies deprivation by measuring housing in poor condition and houses without central heating. Outdoors, air quality is measured across several parameters and the number of road traffic accidents involving injury to pedestrians and cyclists is incorporated. In terms of Living Environment deprivation, both Areas, 2 \& 3 rank within the $24 \%$ most deprived in England.

From these measures a pattern is evident in the area's overall EIMD rankings: two pockets of relative deprivation to the north and west of Hackbridge, with relative prosperity to the south 


\section{Mll Macrothink}

of the study area. These measures of deprivation are, in turn, compounded by the health, housing, education, crime and living environment rankings.

Structure of tenure within the housing market

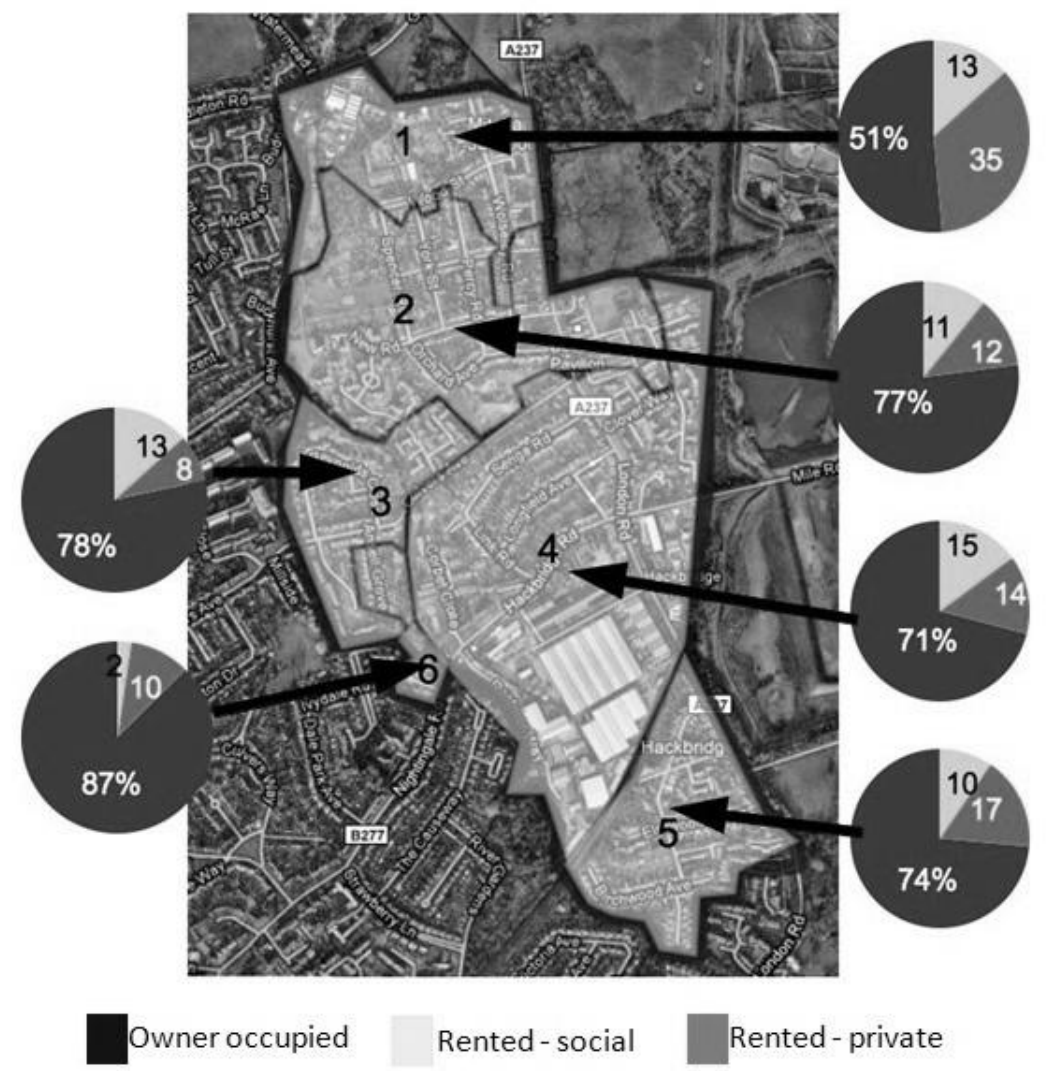

Figure 17. Housing Tenure in Hackbridge. Source: Census 2001 (Crown Copyright 2003)

Figure 17 illustrates the structure of housing tenure within the study area. As the data returns in this instance were at Output Area level (the smallest unit of spatial analysis) it is possible to include a $6^{\text {th }}$ area: a section of 127 households. The data returns (at Output Area level) have been shown within the Lower Super Output Areas (numbered 1 - 5) for the purposes of clarity. As the Figure shows, owner-occupation in Hackbridge is above the English average of $68.72 \%$ in all but one area. Social rented accommodation is below the average of $19.26 \%$ in all areas, and privately rented accommodation exceeds the average figure of $8.80 \%$ in all areas but one.

\section{An area-based analysis}

The following relates the socio-demographic data to the environmental profile. This is achieved by way of an area-based analysis, linking levels of energy consumption and carbon emissions to the structure of tenure and the connection this has to the housing market. As an area-based analysis, this assessment of consumption and emissions by structure of tenure draws upon data profiled from LSOA's 1 and 5. The reasons for focusing attention on these areas are: 


\section{Macrothink}

Environmental Management and Sustainable Development

ISSN 2164-7682 2013, Vol. 2, No. 2

- LSOAs 1 and 5 provide measures of the most and least deprived areas within the urban regeneration boundary. Here, Area 1 is the most deprived with a ranking within the $21 \%$ most deprived areas in England, whereas Area 5 has a much lower ranking within the $30 \%$ least deprived;

- while roughly similar in terms of building type, age, and levels of consumption and emissions, the social-rented sector is prevalent in Area 1, whereas in Area 5 the owner-occupied and private-rented sector are the main sectors of the housing market;

- $\quad$ such an area-based analysis provides evidence to suggest which type of tenure consumes the least or most amount of energy and illustrates the relationship which this, in turn, has to the levels of emissions within the housing market.

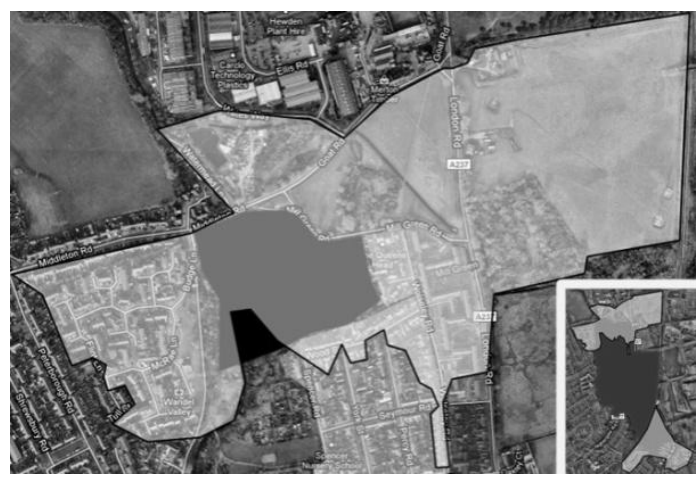

\begin{tabular}{|c|c|c|c|c|c|c|c|}
\hline \multirow[t]{2}{*}{ Type } & \multirow[t]{2}{*}{ Age } & \multirow[t]{2}{*}{ HA } & \multirow{2}{*}{$\begin{array}{c}\text { Average } \\
\text { Energy } \\
\text { Consumption } \\
\text { (kWh p.a.) }\end{array}$} & \multirow{2}{*}{$\begin{array}{c}\text { Average } \\
\text { CO }^{2} \\
\text { Consumption } \\
\text { (kg p.a.) }\end{array}$} & \multicolumn{3}{|c|}{ Tenure (\%) } \\
\hline & & & & & $\begin{array}{c}\text { Owner } \\
\text { Occupied }\end{array}$ & $\begin{array}{l}\text { Private } \\
\text { Rented }\end{array}$ & $\begin{array}{l}\text { Social } \\
\text { Rented }\end{array}$ \\
\hline $\mathrm{I}$ & $1990 \mathrm{~s}$ & 1 & 13631 & 5861 & 80 & 12 & 8 \\
\hline $\mathrm{C}$ & $1930 \mathrm{~s}$ & 2 & 19248 & 5841 & 29 & 15 & 56 \\
\hline $\mathrm{B}$ & 1890-1920 & 3 & 31204 & 7807 & 80 & 12 & 8 \\
\hline Total & & & 64083 & 19509 & & & \\
\hline Average & & & 21361 & 6503 & & & \\
\hline
\end{tabular}

Figure 18. Profile of housing, energy consumption and tenure within the most deprived area of Hackbridge (LSOA 1)

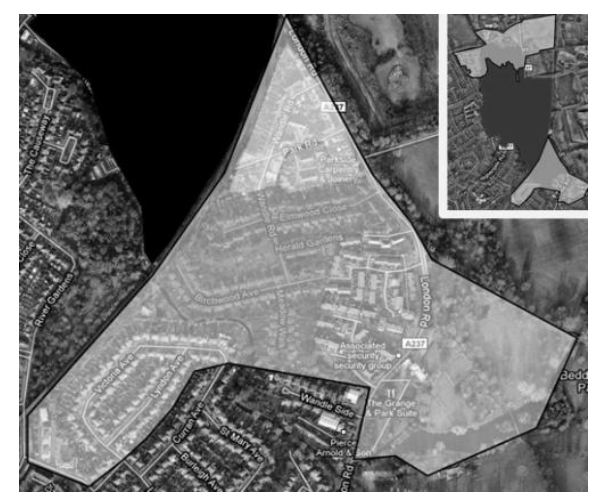




\begin{tabular}{|c|c|c|c|c|c|c|c|}
\hline \multirow[t]{2}{*}{ Type } & \multirow[t]{2}{*}{ Age } & \multirow[t]{2}{*}{ HA } & \multirow{2}{*}{$\begin{array}{c}\text { Average } \\
\text { Energy } \\
\text { Consumption } \\
\text { (kWh p.a.) }\end{array}$} & \multirow{2}{*}{$\begin{array}{c}\text { Average } \\
\text { CO }^{2} \\
\text { Consumption } \\
\text { (kg p.a.) }\end{array}$} & \multicolumn{3}{|c|}{ Tenure (\%) } \\
\hline & & & & & $\begin{array}{c}\text { Owner } \\
\text { Occupied }\end{array}$ & $\begin{array}{l}\text { Private } \\
\text { Rented }\end{array}$ & $\begin{array}{c}\text { Social } \\
\text { Rented }\end{array}$ \\
\hline $\mathrm{B}$ & 1896-1913 & 18 & 31204 & 7807 & 87 & 10 & 3 \\
\hline $\mathrm{L}$ & $1990 \mathrm{~s}$ & 19 & 13791 & 4618 & 87 & 10 & 3 \\
\hline $\mathrm{F}$ & Late 1930 s & 20 & 23626 & 6420 & 85 & 3 & 12 \\
\hline Total & & & 68621 & 18845 & & & \\
\hline Average & & & 22874 & 6282 & & & \\
\hline
\end{tabular}

Figure 19. Profile of housing, energy consumption and tenure within the least deprived area of Hackbridge (LSOA 5)

Notes on Figures 18 and 19:

"Type" refers to the housing model applied in the Energy Options Appraisal [see Figure 7: Hackbridge by House Type]

"Age" refers to the approximate year of build, as designated in the Energy Options Appraisal "HA" refers to the designated localities of similar housing stock in the Hackbridge Study Area, as detailed in the Energy Options Appraisal. Twenty areas of similar housing stock were identified and are used here to show the different housing stock within the lowest-ranking Lower Super Output Area (EIMD 2007) and the highest-ranking LSOA.

Energy and $\mathrm{CO}_{2}$ data has been taken from the Energy Options Appraisal

"Tenure" data has been taken from the Census 2001 at Output Area level. The HA (areas of similar housing) are smaller than Output Areas therefore exact counts for each area of housing cannot be provided. The percentages shown represent a best-fit analysis at Output Area level.

Figure 18 illustrates the relationship between the building type and age of construction by Housing Area (HA) 1, 2 and 3, levels of energy consumption and carbon emissions for the same, split across the structure of tenure. As this illustrates, HA02 is predominantly social-rented in terms of tenure type and has an energy consumption rate of 19,248 (kWh/p.a.), 2,113 ( $\mathrm{kWh}$ p.a.) or $11 \%$ below the overall average for the owner-occupied, private-rented and social rented sectors of the housing market in LSOA 1. Figure 19 goes on to illustrate the same relationships for HAs 18, 19 and 20 in LSOA 5. Here the structure of tenure is predominantly owner-occupied and private-rented and the average energy consumption is 21,926 (Kwh/p.a.), 565 (Kwh/p.a.), or 3\% higher than the average for LSOA 1. 


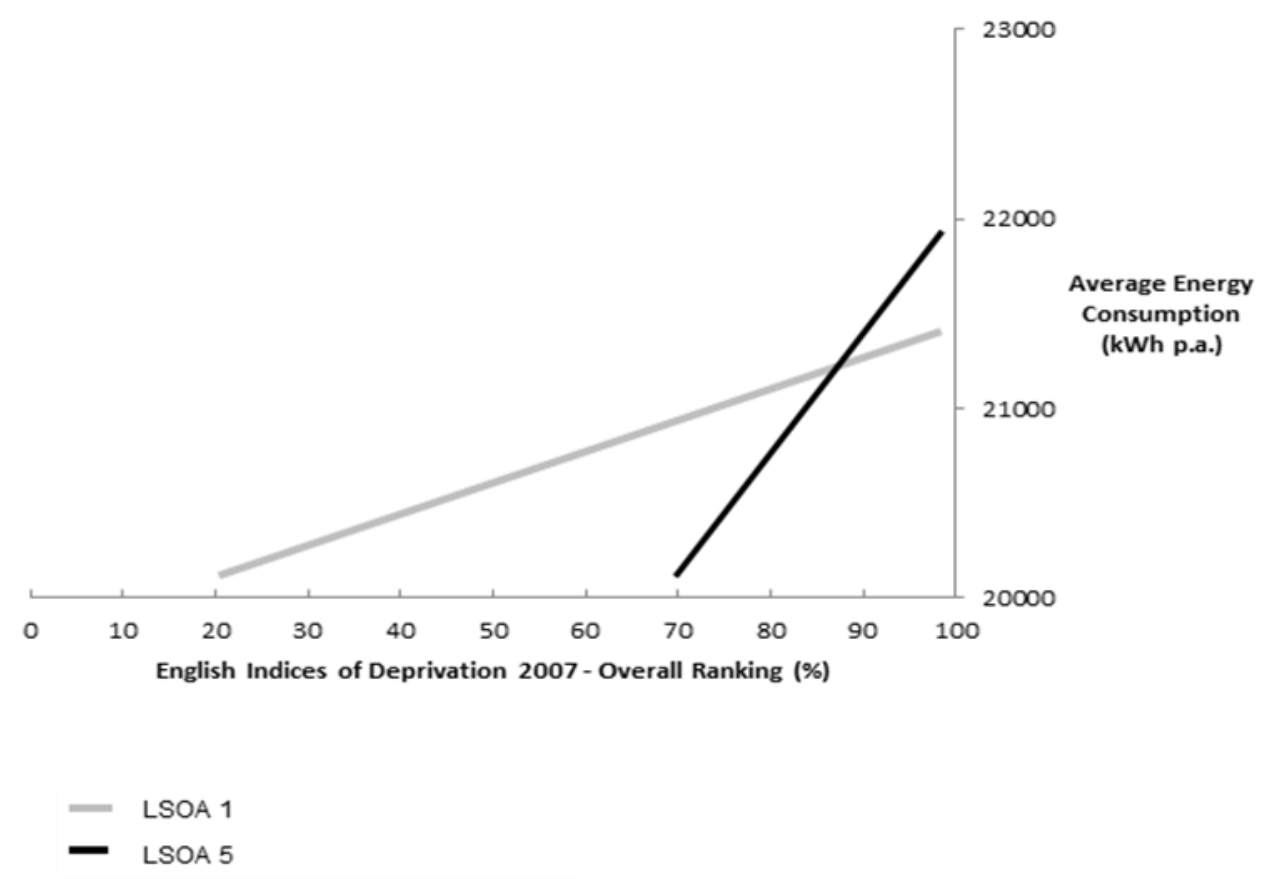

Figure 20. The relationship between deprivation and energy consumption in LSOA 1 and LSOA 5

The diagram illustrates deprivation and energy consumption values for LSOA 1 and LSOA 5 only. It is not intended to suggest a linear relationship between deprivation and energy consumption.

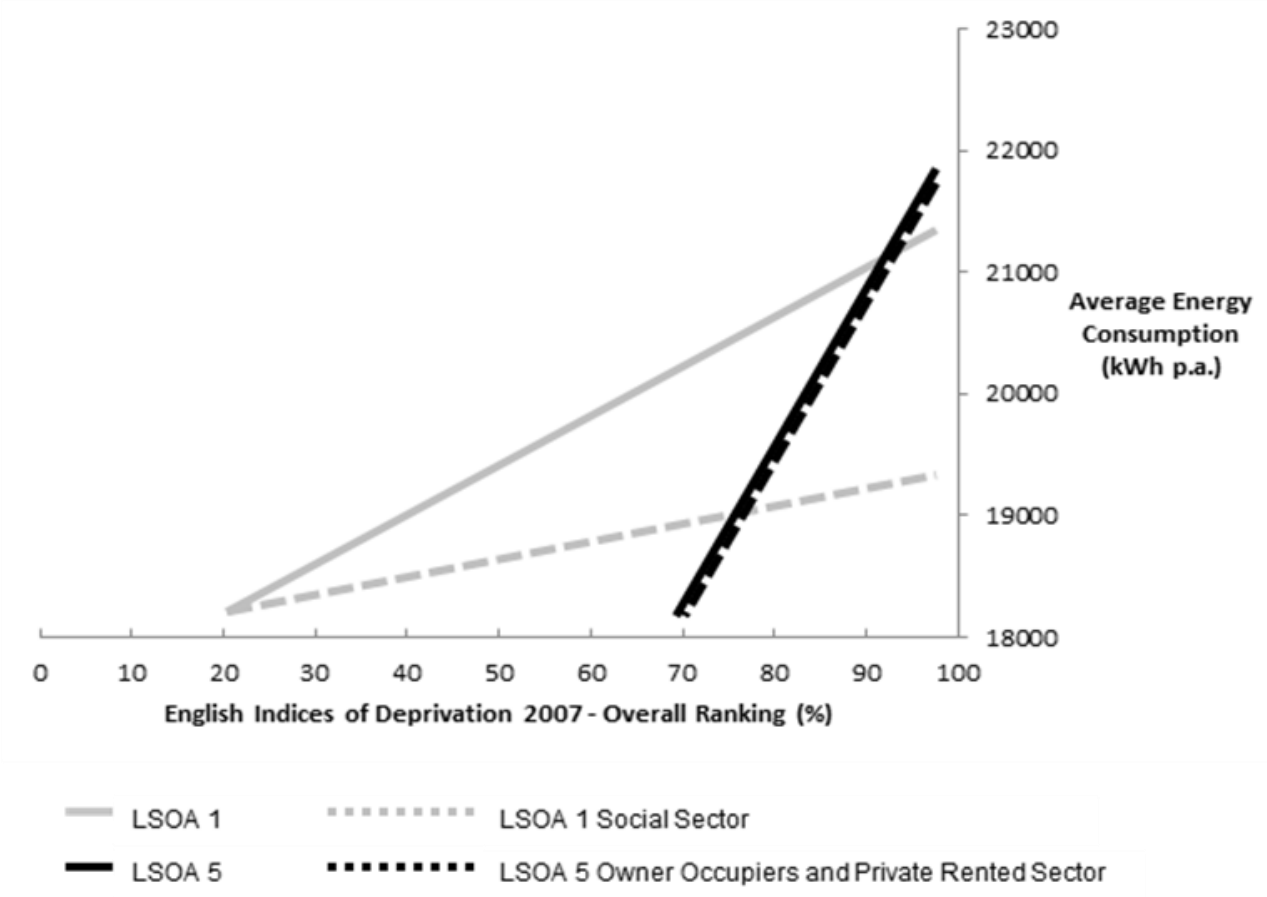

Figure 21. The relationship between deprivation and energy consumption in the social and owner occupier (including private rental) sectors 


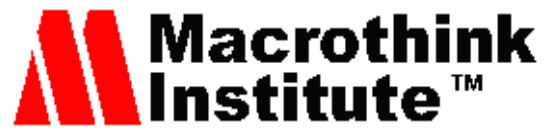

Figure 20 illustrates that LSOA 1 (HAs 1, 2 and 3), located within the 21\% most deprived in England, has the lowest levels of energy consumption and LSOA 5, situated within the 29\% least deprived in England (HAs 18,19 and 20) the highest. Figure 21 also illustrates the levels of energy consumption within the $21 \%$ most and 29\% least deprived LSOAs (1 and 5 respectively) and shows how they are split across the social-rented, owner-occupied and private rented sectors. Within the social-rented sector of LSOA 1 (HA 2), it illustrates the average level of consumption to be 19,248, whereas in LSOA 5 (HA 18, 19 and 20) this is shown to be 21,926 , or $14 \%$ higher for the owner occupied and private rented tenures..

As the $\mathrm{CO}_{2}$ emission levels are similar for both LSOAs 1 and 5 (HAs 1, 2, 3 and 18, 19 and $20)$, they are not seen as warranting such an area-based analysis.

\section{Conclusions}

The case-study which has been chosen to demonstrate the strategic value of mass retrofits in the housing sector is that known as the Hackbridge project. It has been chosen because this project offers a particularly good example of the response made by the London Borough of Sutton to move beyond the state-of-the-art and underpin their vision of urban regeneration with a Masterplan. In particular, within a Masterplan that is not only capable of supporting a programme of renewal, but which also enables the redevelopment of properties with an existing use, by means of adaptation and renovation. That is to say, by way of and through a mass retrofit, designed to reduce rates of energy consumption and levels of carbon emissions in line with the targets which the UK Government have laid down for the housing sector under the 2008 Climate Change Act.

The issue which this paper has with the Hackbridge project relates to the environmental profile which this adaption strategy is based on. It is found wanting for the simple reason the Energy Options Appraisal is not clear as to whether the benefits generated from the forecast rates of energy consumption and levels of carbon emissions, will be spread equally amongst all residents. The reason for this - the paper suggests - is simple: it is because, in order to clarify the distribution of benefits generated, it is necessary for the institutional arrangement supporting the regeneration to first of all "baseline" the social-demographic composition of Hackbridge. Then, draw upon the results of this analysis as the means to assess whether this "innovative" environment has the capacity to carry the energy consumption and carbon emissions targets the "mixed use redevelopment scheme" sets for the transformation of Sutton into a sustainable suburb.

The socio-demographic baseline of the study area has been compiled using data from the English Indices of Deprivation, 2007 and 2001 Census. The results of this analysis have been aggregated at Lower Super Output Area level and the overall ranking of these areas shows a mix of relatively deprived and prosperous residents. In expanding this social-demographic baseline to also include data on building type, age, levels of consumption and emissions across the structure of tenure within the housing market, it has been possible for the analysis to cross reference the rate of energy consumption and level of carbon emissions within these areas to the structure of tenure. 
This quite clearly demonstrates the value of grounding urban morphology not so much in technical matters, but in the social, environmental and economic relationships whose forces do much to set the surface-to-volume and passive-to-non-passive area measures in the specific forms (i.e. neighbourhoods of district centres) drawn attention to by (Ratti, Baker and Steemers 2005) and subjected to a detailed baseline analysis in this paper. For as a baseline the analysis serves to enrich the content of such measures by drawing attention to the design and construction of house types, structure of tenure and occupational behaviours by the user groups associated with the context-specific form the retrofit proposal takes on. That context-specific form which the retrofit proposal takes on and that which in turn makes up the content of the transformation. That content which otherwise would fail be captured in any such baseline analysis, go unnoticed and be left out of the transformation.

These observations be summarised as follows:

- housing built pre-1918 on average consumes 56\% more energy and emits $41 \%$ more $\mathrm{CO}_{2}$ than houses built post-2001;

- the older housing stock is the worst performer in terms of energy efficiency and is the most costly to improve;

- within the regeneration boundary this type of housing makes up less than $20 \%$ of the housing stock. Nearly $40 \%$ of the housing stock having been built post-1970 and is already benefitting from many of the measures proposed to save energy and reduce carbon emissions;

- almost one third of Hackbridge residents live in areas which rank within the top $15 \%$ most income-deprived in England, renting their homes from the Local Authority, Registered Social Landlords, Housing Associations or the private-rented sector. These homes in the social-rented sector have been shown to consume less energy and to emit less $\mathrm{CO}_{2}$ than other housing type of a similar age in Hackbridge.

The question this in turn raises the following questions about the transformation: given that the current policy on the retrofit excludes the social-rented sector, the assumptions made about how the energy efficiencies of such a flagship low carbon-zone can be generated at no additional environmental costs to residents prompts a number of questions. This is because in its current form the commitment to the mass retrofit may be seen as being divisive, not just in terms of the volume and area, but extent, breadth and depth of the transformation which it lays out as measures for improving the energy efficiency and carbon footprint of the housing market. For under the existing proposal, housing situated within the social rented sector shall be excluded from the retrofit and remain with an energy efficiency and carbon emission rating of $75 \%$ (Band $\mathrm{C}$ rating). While under the retrofit proposals covering the owner-occupied and private rented sectors of the housing market, the 50\% improvements in energy efficiency and carbon emissions for this sector are not only forecast to improve their standing from Band $\mathrm{E}$ to $\mathrm{C}$, respectively $(69-80 \%)$, but also holdout the prospect of meeting the targets set under the UK's Climate Change Act for 2020. 
As such it might be said such critically-insightful observations and questions they in turn raise, literally speak volumes about the context-specific transformation such retrofit projects pave the way for not just as a type of building design, construction system, or set of occupational behaviours, but structure of tenure and are certainly not passive as to the content of the energy efficient-low carbon zones these "areas" are proactive in amassing within the housing market.

\section{References}

Bourdic, L., Serge, S., \& Nowacki. C. 2012: “Assessing cities: a new system of cross-scale spatial indicators.” Building Research and Information, 40(5), 592-605.

Deakin, M., Campbell, F., \& Reid, A. (2012a). "The mass-retrofitting of an energy efficient low-carbon zone: baselining the urban regeneration strategy, vision, master-plan and redevelopment scheme." Energy Policy, 45, 187-200.

Deakin, M., Campbell, F., \& Reid, A. (2012b). "The mass-retrofitting of an energy efficient low-carbon zone" Energy, 165(4), 197-208.

Department for Communities and Local Government. (2008). The English Indices of Deprivation 2007, HMSO, Crown Copyright 2008

London Borough of Sutton. (2008). Draft Development Plan Document: Core Planning Strategy. Available at http://www.sutton.gov.uk/CHttpHandler.ashx?id=3429\&p=0

London Borough of Sutton. (2008). Energy Options Appraisal for Domestic Buildings in Hackbridge. Produced by Parity Projects. Available at: http://www.sutton.gov.uk/CHttpHandler.ashx?id=5173\&p=0

Office for National Statistics. (2001). Census: Digitised Boundary Data (England and Wales). ESRC/JISC Census Programme, Census Geography Data Unit (UKBORDERS), Census Dissemination Unit, Mimas (University of Manchester)

One Planet Sutton. Hackbridge Sustainable Suburb: Draft Sustainability Action Plan. Available at: http://www.sutton.gov.uk/CHttpHandler.ashx $? i d=5175 \& p=0$

Ratti, C., Baker, N., \& Steemers, K. (2005). "Energy consumption and urban texture." Energy and Buildings, 37(7), 762-776.

Salat, S. (2009). "Energy loads, $\mathrm{CO}_{2}$ emissions and building stocks: morphologies, typologies, energy systems and behaviour.” Building Research and Information, 37(5/7), 598-609.

2001 Census, Output Area Boundaries. Crown copyright 2003.

\section{Copyright Disclaimer}

Copyright reserved by the author(s).

This article is an open-access article distributed under the terms and conditions of the Creative Commons Attribution license (http://creativecommons.org/licenses/by/3.0/). 